\title{
Construction and Thinking of the Ocean Hydrological Instruments Course Facing for Graduate Students
}

\author{
Song Ye ${ }^{\mathrm{a}}$, Shang-shu Ren ${ }^{\mathrm{b}^{\star}}$, Long Zhang ${ }^{\mathrm{c}}$ and Shu-dao Zhou ${ }^{\mathrm{d}}$ \\ Meteorological and Ocean College of PLA University of Science and Technology, \\ Nanjing, 211101, China \\ ayesong999@hotmail.com, b510260307@qq.com, czhanglonglxy@163.com, \\ dzhousd70131@sina.com
}

Keywords: Teaching Reform; Ocean Hydrological Instrument Course; Teaching Design; Postgraduate Education

\begin{abstract}
For the course of ocean hydrological instrument, the basic idea of course construction is generalized by summarizing the experience of teaching reform. According to the characteristics of the graduate teaching, a detailed teaching plan is designed. And the teaching form is briefly introduced. The pertinence of the teaching plan and the difficult points in the teaching are pointed out. This paper provides some suggestions for the graduate education in military colleges, which is helpful to the teaching reform of them.
\end{abstract}

\section{Introduction}

Ocean hydrological instrument is a postgraduate course offered by PLA University of Science and Technology to meet the needs of teaching and research in the field of the ocean. At present, other colleges and universities have not yet opened similar courses. This course is of great significance to the construction of ocean observation system and the research of ocean observation instruments. This course was included in the training program for graduate students in 2008 and first implemented in the spring of $2011^{[1]}$. This course consists of 40 classes and the teaching materials are prepared by the main teacher. The main teaching methods include theoretical teaching, literature reading, and special discussion and so on. The course's teaching object are the graduate students who major in measurement and control technology and instrument, marine environment detection and signal processing ${ }^{[2]}$.

\section{The Basic Idea of Course Construction}

The teaching goal of this course is to make the students master the working principle of all kinds of ocean hydrological instruments and improve the ability of the research of ocean hydrological instruments. Combined with the actual needs of the marine hydrological environment monitoring, students are encouraged to carry out independent study and research, and have the ability to solve practical problems, so that we can realize the goal of training high level national defense technical personnel.

In the past five years of teaching, the teaching team has always insisted on innovative teaching ideas. According to the rapid development of technology in this area, we have continuously improved the ability and quality of students by expanding the knowledge surface and following the development trend closely. On the basis of mastering basic knowledge, students are encouraged to continue to improve the ability of independent learning and innovation. In the teaching practice, students and teachers can share the joy, passion and emotion brought by team spirit and academic research.

\section{The Arrangements of Teaching Content}

According to the training program of graduate students, we are committed to the development of national defense technology and reflect the military characteristics. Based on the teaching principles of application and innovation, many of the research topics on the design and innovation of marine 
hydrological instruments have been designed to meet the special needs of national defense construction ${ }^{[3]}$. High level academic papers were selected as the course literature materials, combined with the contents of textbooks; the teaching contents are constantly enriched.

The teaching content is divided into four stages: the application background of marine hydrological instrument, the classic case analysis, national defense applications and harvest sharing.

The learning stage of application background includes: the overview of ocean, ocean environmental factors, regional ocean environment and ocean observation. Literature reading and classroom discussion are the main teaching methods.

The classic case analysis includes the following: the challenge of ocean observation, ocean observation platform and its development trend, tides, waves, sea ice, sea surface temperature, salinity and current measuring instrument ${ }^{[4]}$. The teaching content mainly includes the textbook, the marine survey pictures and images, the multimedia teaching material and so on.

The learning stage of defense application mainly includes two topics: multi-factor ocean observation instrument and the concept and design of NMOHEMS and WTTVS. The teaching content mainly comes from the research result of the teaching team. The main form of the harvest sharing stage is the exchange report according to the student's academic papers and experimental results.

\section{The Organization Form of Teaching}

The course teaching is carried out in the following ways: literature reading, theory explanation, special lecture, problem discussion and report communication.

Group discussion is the key part of this course. According to the teaching progress, the students can choose the right topic according to their interests and research directions. And the research plan is formulated under the guidance of the teacher. The teaching time is arranged as follows: the theory teaching occupies 20 24 hours, the topic discussion accounts for 10 12 hours, the experimental design accounts for $2 \sim 4$ hours, the exchange report occupies $2 \sim 4$ hours.

In order to excavate potential and encourage creativity, extracurricular learning plan is implemented. Extracurricular learning tasks include the following: literature reading, thesis writing, programming, special research and so on.

In the evaluation stage, the evaluation system is established to measure the comprehensive quality of the students. Finally, the comprehensive results are given based on class discussions, exchange reports, experimental design and academic papers. Among them, class discussion accounts for $30 \%$, experimental design accounts for $20 \%$, exchange report accounts for $10 \%$, academic paper accounts for $40 \%$.

On the basis of summarizing the experiences in previous teaching, other successful cases of practical teaching have also been used for reference. The theory and practice are combined by oceanographic research which helps to enhance students' sense of military, mission and responsibility.

The practice teaching of oceanographic research includes the following five aspects. The flow chart is shown in Fig. 1.

(1)The stage of task mobilization and preparation

In view of the particularity of the practice environment, the basic knowledge education related to the navy is increased, including naval etiquette, naval rules and regulations and requirements for offshore operations ${ }^{[5]}$.

(2) Safety assurance on the way

Because of a certain danger exists in the practice environment, the spirit of cooperation and the sense of discipline must be strengthened in practice

(3) Maritime practice stage

We should strive to strengthen the flexibility of teaching and deepen the understanding of the various departments and various equipment of the ship. Most important of all, the application methods of the ocean hydrological instruments need to be deeply applied in practice. In addition, 
the psychological counseling needs to be carried out for the students who are difficult to adapt to the ocean environment.

\section{(4) School seminar}

After returning to school, the practical materials should be sorted out and the exchange discussion should be organized, which is an effective way to strengthen the professional knowledge and stimulate the learning enthusiasm.

(5) Summary and performance evaluation

A summary of the practice course needs to be carried out, and a comprehensive assessment of the students needs to be given.

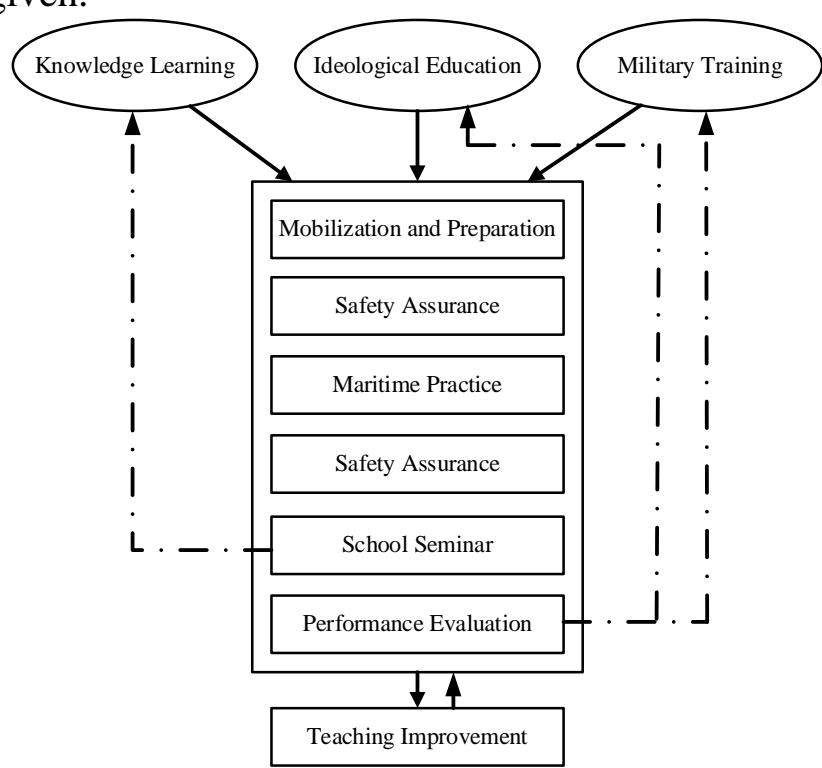

Fig. 1 The flow chart of oceanographic research.

The teaching practice of oceanographic research helps to improve the students' professional knowledge, military level and physical quality, which has great significance to the growth of students ${ }^{[6]}$.

\section{Establish a Scientific Evaluation System}

The oceanographic research involves a variety of special environment, which is a good exercise for students' physical, psychological and will. In addition to professional knowledge, the evaluation system should also include a variety of factors such as discipline awareness, team awareness and fighting spirit ${ }^{[7]}$. Only in this way can we make an objective and accurate evaluation of the students' performance.

The comprehensive evaluation should include two parts: the practice result and the physical quality. The proportion of each part is shown in table 1 and table 2 .

Table 1 The evaluation method of practice performance

\begin{tabular}{cccc}
\hline Homework and Discussion & Practice Report & Students Evaluation & Teacher Evaluation \\
\hline $30 \%$ & $40 \%$ & $10 \%$ & $20 \%$ \\
\hline
\end{tabular}

Table 2 The evaluation method of physical quality

\begin{tabular}{cc}
\hline First level & Poor \\
\hline Second level & Common \\
\hline Third level & Good \\
\hline Fourth level & Great \\
\hline
\end{tabular}

\section{Conclusion}

Due to the big difference of knowledge background between the students, it is necessary to make specific adjustments to the teaching plan in the teaching process. And we should guide students to 
examine the development trend of the ocean hydrological instruments through the professional perspective of instrument science. In addition, the students should master the military requirements and design research of ocean observation instruments. These are the difficult problems in teaching.

In this paper, the theory and practice of the teaching of ocean hydrological instruments are combined. And a new teaching idea, which can make knowledge, quality and ability to improve at the same time, is discussed. It has the reference significance to the teaching and practice of the related course in Military Academy.

\section{Acknowledgment}

This work is supported by the National Natural Science Foundation of China (NSFC) (No. 40976062), the Natural Science for Youth Foundation (NSYF) (No. 41406107), and the Natural Science Foundation of Jiangsu Province (No. BK2009062 and No. BK2012513).

\section{Reference}

[1] Ye Song, Wang Xiao-lei, Chen Yi-de. The organization of military academies and the evaluation method of Marine Survey Practice Teaching (In Chinese) [A]. College of earth science courses forum[C].Beijing: Higher Education Press, 2010, 376-379.

[2] Ye Song, Liang Miao-yuan, Zhou Shu-dao. Utilization and regeneration of multiple teaching resources in the teaching of marine hydrological instruments (In Chinese) [A]. College of earth science courses forum[C].2012, 7.

[3] Liu Xian-jun. On the students as the center (In Chinese) [J]. Research on Higher Education, 2012, 33(8):1-6.

[4] Sun Yue. An effective way to cultivate students' Creative Ability -- Discussion Teaching (In Chinese) [J]. China Electric Power Education, 2010, 27:54-56.

[5] Li Min-xin, Dai Shu-xing. New talent training of foreign military academies and Its Enlightenment (In Chinese) [J]. Journal of Higher Education Research, 2004, 27(4):32-34.

[6] Jiang Zhi-jun, Li Xiang-bin, Gu Hui. The characteristics and development trend of Foreign Military Academies (In Chinese) [J]. Naval colleges and universities education, 1998, 32:70-74.

[7] Huang Zhi-yong, Chen Tie-zhu, Sun Tao. Innovation of teaching content system in Military Academies (In Chinese) [J]. Research on Higher Engineering Education, 2008, 3:103-106. 